\title{
Prolonged activation of S6K1 does not suppress IRS or PI-3 kinase signaling during muscle cell differentiation
}

\author{
D Lee Hamilton, Andrew Philp, Matthew G MacKenzie and Keith Baar*
}

\begin{abstract}
Background: Myogenesis in C2C12 cells requires the activation of the PI3K/mTOR signaling pathways. Since mTOR signaling can feedback through S6K1 to inhibit the activation of PI3K, the aim of this work was to assess whether feedback from S6K1 played a role in myogenesis and determine whether siRNA mediated knockdown of S6K1 would lead to an increased rate of myotube formation.

Results: S6K1 activity increased in a linear fashion following plating and was more than 3-fold higher after Day 3 of differentiation (subconfluent $=11.09 \pm 3.05$, Day $3=29.34 \pm 3.58$ ). IRS-1 levels tended to increase upon serum withdrawal but decreased approximately 2 -fold (subconfluent $=0.88 \pm 0.10$, Day $3=0.42 \pm 0.06$ ) 3 days following differentiation whereas IRS-2 protein remained stable. IRS- 1 associated p85 was significantly reduced upon serum withdrawal (subconfluent $=0.86 \pm 0.07$, Day $0=0.31 \pm 0.05$ ), remaining low through day 1 . IRS-2 associated p85 decreased following serum withdrawal (subconfluent $=0.96 \pm 0.05$, Day $1=0.56 \pm 0.08$ ) and remained suppressed up to Day 3 following differentiation (0.56 \pm 0.05$)$. Phospho-tyrosine associated p85 increased significantly from subconfluent to Day 0 and remained elevated throughout differentiation. siRNA directed against S6K1 and S6K2 did not result in changes in IRS-1 levels after either 48 or 96 hrs. Furthermore, neither 48 nor 96 hrs of S6K1 knockdown caused a change in myotube formation.
\end{abstract}

Conclusions: Even though S6K1 activity increases throughout muscle cell differentiation and IRS-1 levels decrease over this period, siRNA suggests that S6K1 is not mediating the decrease in IRS-1. The decrease in IRS-1/2 associated p85 together with the increase in phospho-tyrosine associated p85 suggests that PI3K associates primarily with scaffolds other than IRS-1/2 during muscle cell differentiation.

\section{Background}

During development, multinucleated muscle fibers form from the terminal differentiation and fusion of individual myogenic progenitors, or myoblasts [1]. This process is recapitulated during the process of skeletal muscle regeneration in response to trauma, disease, or contraction mediated injury [2]. As a result of the importance of this process, the regulation of myoblast differentiation and fusion has been widely studied in tissue culture using both primary and transformed myoblasts. In 2-dimensional cell culture, myoblasts are maintained in a proliferative state by providing media with high serum content

\footnotetext{
*Correspondence: kbaar@ucdavis.edu

${ }^{1}$ Division of Molecular Physiology, James Black Centre, University of Dundee, Dundee, UK

Full list of author information is available at the end of the article
}

and maintaining a relatively low confluence. Growing the myoblasts to full confluence or changing to a low serum growth media induces terminal differentiation. The combination of high confluence and low serum growth media induces both myoblast differentiation and fusion, resulting in the formation of myotubes.

Myogenesis is regulated at multiple levels. The degree of confluence and the level of growth factors within the media are transduced by a series of kinase signaling pathways [3]. How myoblasts signal confluence is currently unclear. At high confluence, cadherins are thought to signal to p38 MAPK either through a Rho kinase (ROCK) [4] or Cdo/JLP dependent [5] mechanism. The activation of p38 enhances the transcriptional activity of several MRFs [6] and in this way may initiate myoblast differentiation. 
Growth factor regulation of myogenesis is better understood. When growth factors are low, myoblasts begin to secrete IGF-II, which is required for, and determines, the rate of differentiation [7]. IGF-II is thought to initiate an autocrine signaling cascade through the IGF-I receptor [8] and the insulin receptor substrates (IRS) 1 and 2, that activates MAPK and PI3K (phosphoinositide3 kinase) [9]. PI3K activates PKB (protein kinase B/akt), and either PI3K or PKB is sufficient for myoblast differentiation and fusion [10]. PI3K and PKB drive differentiation by inhibiting GSK3 [11], increasing the transcriptional activity of MyoD [12], and activating the mammalian target of rapamycin (mTOR; [13]. mTOR expression and activity increase during differentiation [14] leading to an increase in the activity of its downstream target, S6K1 $[14,15]$. However, neither the kinase activity of mTOR nor S6K1 are required for differentiation [16]. Even though S6K1 activity is not required for muscle cell differentiation, S6K1 can regulate the activation of PKB by IGF-II through IRS-1 protein, mRNA, and activity [17-19]. Where S6K1 is constitutively active, as in TSC2-/- cells, IRS-1 function is potently suppressed [17].

Considering the important role of the IGF-II signaling through IRS-1 to PKB in the control of differentiation, and the ability of S6K1 to block IRS-1 signaling, it seems paradoxical that S6K1 would be activated during differentiation. The aim of the current work was to assess whether the negative feedback between S6K1 and IRS-1 was maintained during myogenesis. We hypothesised that the activation of S6K1 during differentiation would correlate with a reduction in IRS-1 function and that inhibiting S6K1 activation would increase myotube formation.

\section{Results}

\section{Myotube formation and muscle specific gene expression}

Three hours after plating, the subconfluent cells attached and spread to reach $\sim 70 \%$ confluence (Figure 1). At Day 0 , the cells formed a confluent monolayer. At Day 1, the cells began to align and fuse and expressed low levels of myosin heavy chain (Figure 1B). By Day 3 large numbers of myotubes and high myosin heavy chain levels were evident. These time points were selected since the subconfluent to Day 0 interval could be used to determine contact-dependent events, the Day 0 to Day 1 interval could be used to identify growth factor-dependent differentiation events, and the 3 day point could be used to determine the effects of an intervention on fusion.

The percentage of nuclei stained with MyoD or myogenin and the levels of myosin heavy chain were assessed to give a measure of the stage of myogenesis. Nuclei stained with MyoD increased approximately 2-fold upon reaching confluence (Figure $1 \mathrm{C}$; subconfluent $=22 \pm$ $7.3 \%$; versus Day $0=47 \pm 5.1 \%$ ), remained elevated once growth factors were removed for 24 hrs (Day $1=46.8 \pm$ $6.4 \%$ ), and returned towards subconfluent levels following another $48 \mathrm{hrs}$ in DM (Day $3=31 \pm 4.1 \%$ ). Myogenin expression increased progressively following plating, peaking $72 \mathrm{hrs}$ following serum withdrawal (Figure 1C).

\section{Differentiation induced signaling}

To begin to understand the dynamics of the signaling events that may lead to differentiation, the phosphorylation of p44/42 at Thr202/Tyr204 and PKB at Thr308, and the phosphorylation and activity of S6K1 were determined at the various stages of differentiation. The phosphorylation of $\mathrm{p} 44 / 42$ decreased significantly upon reaching confluence and remained significantly suppressed up to $72 \mathrm{hrs}$ following serum withdrawal (Figure 2A). Phosphorylation of $\mathrm{PKB}$ on the other hand appears to have a bi-phasic response. Upon reaching confluence, PKB phosphorylation decreased approximately 3-fold $(\mathrm{SC}=0.87 \pm 0.07$, Day0 $=0.32 \pm 0.02)$. From Day 0 to Day 1 , PKB phosphorylation and total protein increased marginally (Day0 $=0.32 \pm 0.02$, Day $1=0.42 \pm 0.02$ ), and then from Day 1 to Day 3, PKB phosphorylation decreased and the total protein increased resulting in a large decrease in the ratio of phospho- to total PKB (Day $3=0.15 \pm 0.01$; Figure 2B). S6K1 phosphorylation and activity increased approximately 3 -fold from SC $(11.10 \pm 3.05)$ to Day 3 $(29.33 \pm 3.57$; Figure 2C).

\section{IRS-1/2 Expression and associated p85}

To better understand the role that IRS- 1 and IRS- 2 play in signaling during myogenesis, IRS1/2 protein level and PI3K association were determined. IRS-2 protein (Figure 3B) remains stable throughout the time course, whereas IRS-1 protein tended to increase to Day 1 before reducing approximately 2 -fold by Day 3 (subconfluent $=0.88 \pm$ 0.10 , Day $3=0.42 \pm 0.06$; Figure $3 \mathrm{~A}$ ). The association of IRS-1 with p85 significantly reduced upon serum withdrawal (subconfluent $=0.86 \pm 0.07$, Day $0=0.31 \pm 0.05$ ) Even though the absolute amount of p85 precipitated remain the same at Day 1 and 3, the decrease in total IRS1 protein at Day 3 leads to an increase in the amount of p85 relative to IRS-1 (Figure 3C). IRS-2 associated p85 decreased from subconfluent levels reaching significance on Day 1 (subconfluent $=0.96 \pm 0.05$, Day $1=0.56 \pm 0.08$ ) and remained suppressed up to Day $3(0.56 \pm 0.05$; Figure $3 \mathrm{D})$. Therefore, reaching confluence reduces signaling through IRS-1, while IRS-2 signaling reduces following serum withdrawal.

\section{Knockdown of S6K1 does not alter IRS-1 levels or differentiation}

To determine whether increasing S6K1 activity underlies the decrease in IRS-1 protein and activity, siRNA directed against S6K1 and its homologue S6K2 were transfected into muscle cells prior to differentiation. 


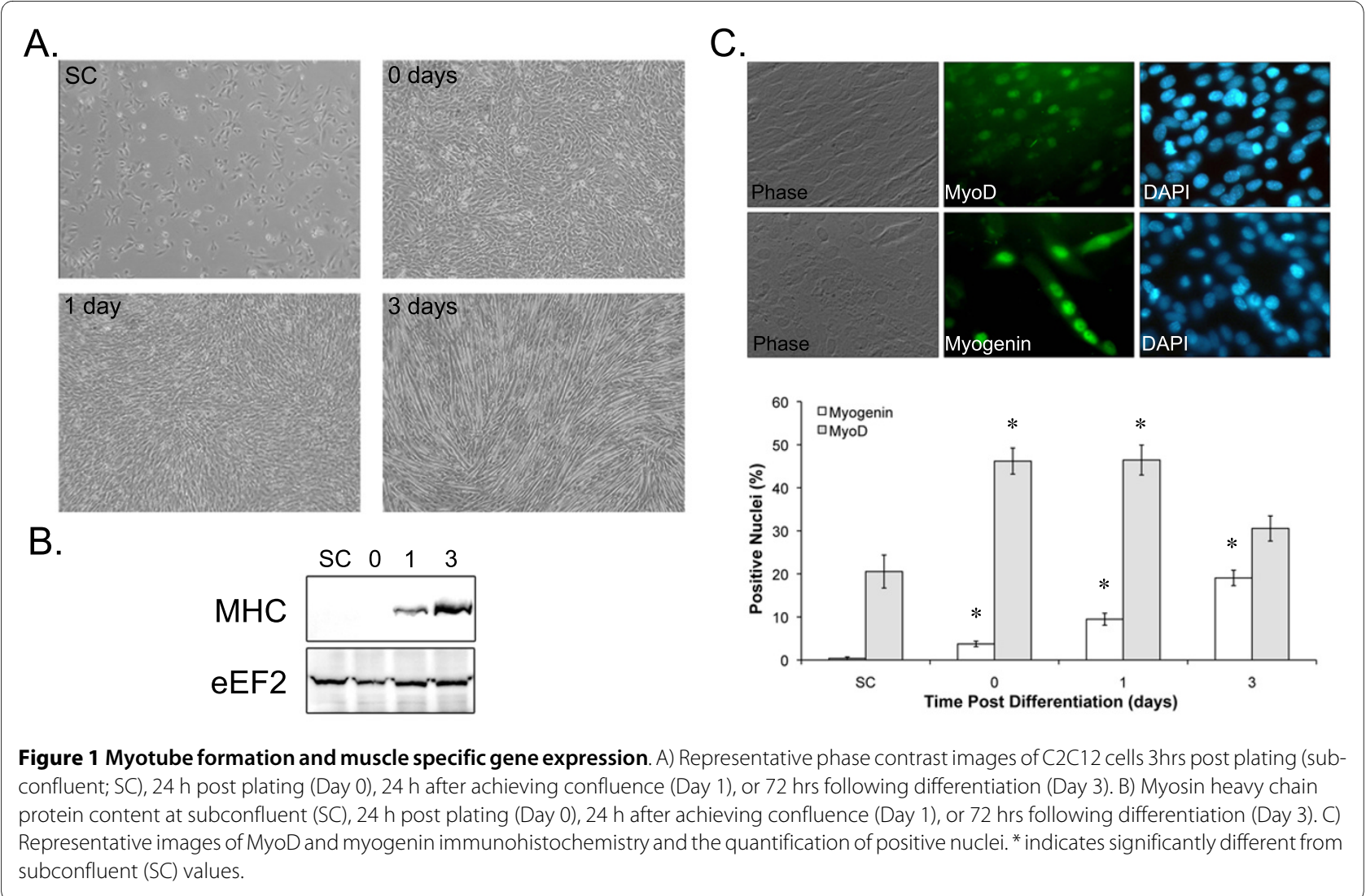

Transfection with siS6K1 for 48 hrs (transfected at SC, collected at Day 1) significantly reduced S6K1 protein levels (Figure 4A). However, despite the robust knockdown of S6K1 there was no effect on IRS-1 protein levels (Figure 4B). To determine whether loss of S6K1 was compensated for by its homologue S6K2, we knocked down S6K2 individually or in combination with S6K1 and measured the effects on IRS-1 levels and differentiation. Knock down of S6K2 or S6K1 and 2 had no effect on IRS1 protein levels (Figure 4B) or myotube formation (data not shown). Since the decrease in IRS-1 protein was not apparent until Day 3, the effects of a more sustained knockdown (collecting the cells at Day 3) on IRS-1 levels and differentiation were determined. The $96 \mathrm{hr}$ knockdown yielded similar results: no increase in IRS-1 protein levels (Figure 4C) and no change in myotube formation (Figure 4D). These data suggest that the physiological activation of S6K1 does not mediate the decrease of IRS1 protein level during myoblast differentiation and has no effect on myotube formation.

\section{Differentiation-induced phosphotyrosine associated p85}

Since PI3K signaling is known to be required for myotube formation, yet IRS-1/2 associated p85 was decreased, phospho-tyrosine associated p85 was determined to assess non-IRS associated PI3K activation. pY associated p85 increased approximately 2-fold $(\mathrm{SC}=0.92 \pm 0.05$, Day $0=1.93 \pm 0.11$; Figure 5 ) upon reaching confluence and remained significantly elevated throughout the 72 hrs of the experiment (Day $3=1.84 \pm 0.05$ ). These data suggest that PI3K is activated within the myoblasts upon reaching confluence and that the predominant route for PI3K signaling is through non-IRS-1/2 phospho-tyrosine complexes.

\section{Discussion}

In $\mathrm{C} 2 \mathrm{C} 12$ cells, S6K1 activity increased almost 3-fold from subconfluence until myotubes were completely formed. Concomitant with the increase in S6K1 activity was a decrease in IRS-1 signaling and protein levels, consistent with the negative feedback loop from S6K1 to IRS1. However, knocking down S6K1 had no effect on IRS-1 protein levels, suggesting that physiological activation of S6K1 during differentiation did not lead to the reduction of IRS-1 protein. Even though IRS-1/2 function decreases during differentiation, phosphotyrosine associated p85 increases at confluence and remains high throughout differentiation. These data suggest that during myogenesis the predominant source of PI3K activity is phosphotyrosine complexes other than IRS-1/2.

S6K1 activity increases substantially from subconfluent C2C12 myoblasts to fully differentiated myotubes. 


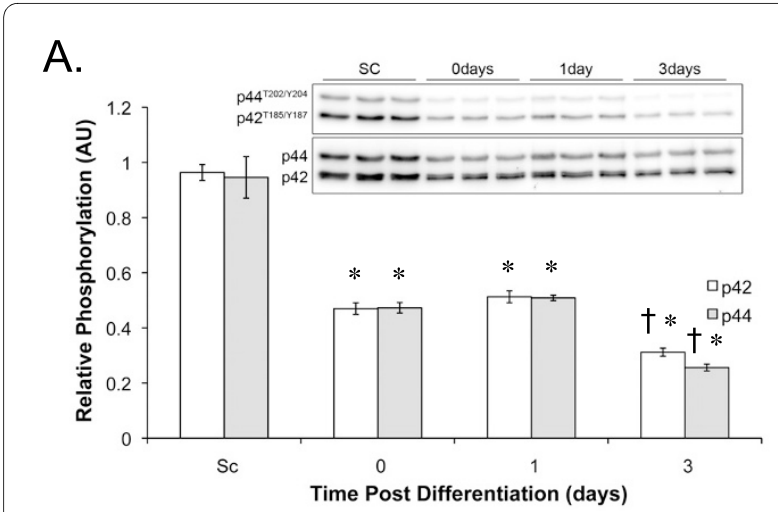

B.

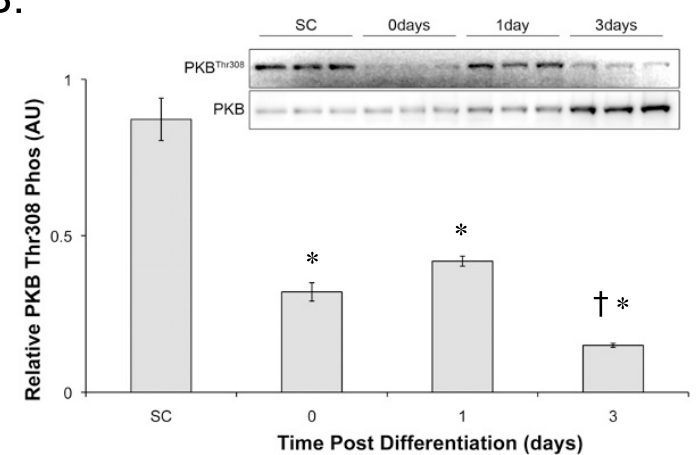

C.
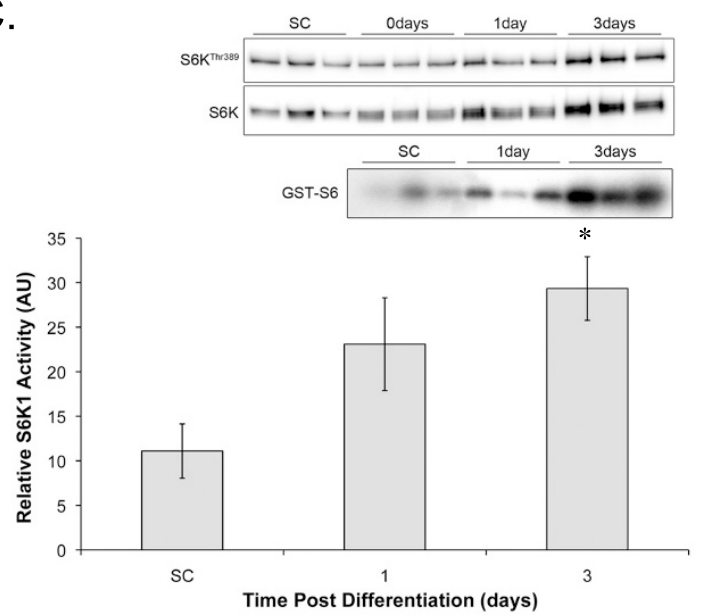

Figure 2 Differentiation decreases p42/44 and PKB signaling whereas S6K activity increases. A) p44/42 MAPK Thr202/Tyr204 phosphorylation relative to total p44/42 (p-p44/42), B) PKB Thr308 phosphorylation relative to total PKB (p-PKB) and C) S6K1 phosphorylation and activity determined relative to total S6K1 3 hrs post plating (subconfluent; SC), $24 \mathrm{~h}$ post plating (Day 0), $24 \mathrm{~h}$ after achieving confluence (Day 1), or 72 hrs following differentiation (Day 3). * indicates significantly different from SC, + indicates significantly different from Day 1. Values were obtained by normalising specific phosphorylation to total protein content as described in methods.

Recently, S6K1 has been identified as a key component of a negative feedback loop in insulin/growth factor signal- ing [19]. This feedback is mediated through serine phosphorylation and direct regulation of IRS-1 protein and mRNA. In differentiated L6 myotubes, activation of S6K1 for as little as $1 \mathrm{hr}$, inhibits insulin stimulated IRS-1 associated PI3K activity [18]. Therefore, we hypothesized that the prolonged activation of S6K1 during myogenesis would lead to a reduction in IRS-1 protein levels. Consistent with this hypothesis, IRS-1 protein declined by more than $50 \%$ between Day 1 and Day 3 of differentiation. Since growth factor mediated differentiation is thought to involve IGF-II signaling through IRS-1 to PI3K and PKB, we further hypothesized that decreasing S6K1 would increase IRS-1 protein and result in greater IGF-II signaling and myoblast differentiation. Contrary to this hypothesis, knockdown of S6K1, its structural homologue S6K2, or both enzymes together had no effect on IRS-1 protein level or muscle cell differentiation. These data suggest that during differentiation S6K1 does not regulate the level of IRS-1 protein or muscle cell differentiation. In agreement with the current work, Park et al $[16,20]$ have elegantly shown that $\mathrm{S} 6 \mathrm{~K} 1$ is not required for muscle cell differentiation but plays an important role in myocyte hypertrophy once differentiation is complete.

Measuring the amount of $\mathrm{p} 85$ associated with a particular scaffolding protein provides an estimate of the PI3K activity of that complex. Due to the requirement on IRS-1 for human myoblast differentiation [21] we had expected that IRS- 1 associated p 85 would be substantially elevated from the point of plating. However, both IRS-1 and IRS-2 associated p85 were significantly suppressed during differentiation. Instead of associating with IRS-1 or 2, PI3K associates with other phosphotyrosine complexes during differentiation in $\mathrm{C} 2 \mathrm{C} 12$ cells. These data do not preclude a role for IRS in myogenesis. Indeed, cross-talk between cell surface receptors and the insulin/IGF-I pathways has recently been described in mice with skeletal muscle lacking $\beta_{1}$-integrins [22]. In mice without $\beta_{1}$-integrins insulin-induced phosphorylation of PKB at Ser473 was impaired even though IRS-1 signaling appeared normal. Since integrins and cadherins interact with integrinlinked kinase (ILK; $[23,24]$, and ILK binds to both PKB and the Ser473 kinase mTORC2 [25], this suggests that cell surface receptors work together with IRS-1 to activate PI3K and PKB. The current data suggest that in differentiating muscle, the interaction between the cell surface receptors and IRS-1 is reversed. At high confluence, cell-cell contact results in the activation of cadherins and integrins [26], which function as high confluence-activated receptors. PI3K can be recruited to cell-cell contacts and activated by cadherin [27], but this has yet to be demonstrated in muscle cells. During differentiation, cadherins are upregulated in C2C12 cells [28], suggesting that they may play an important role in confluence-dependent differentiation. Some researchers 


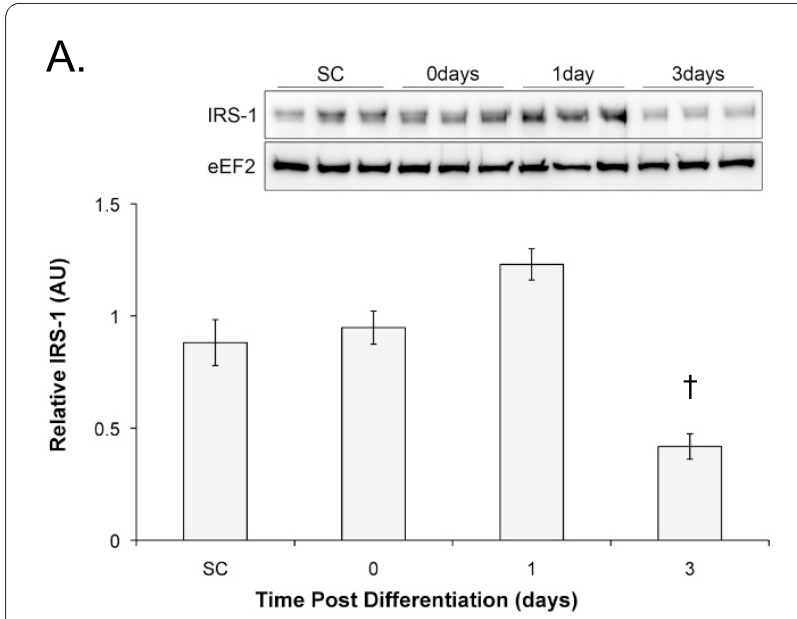

B.
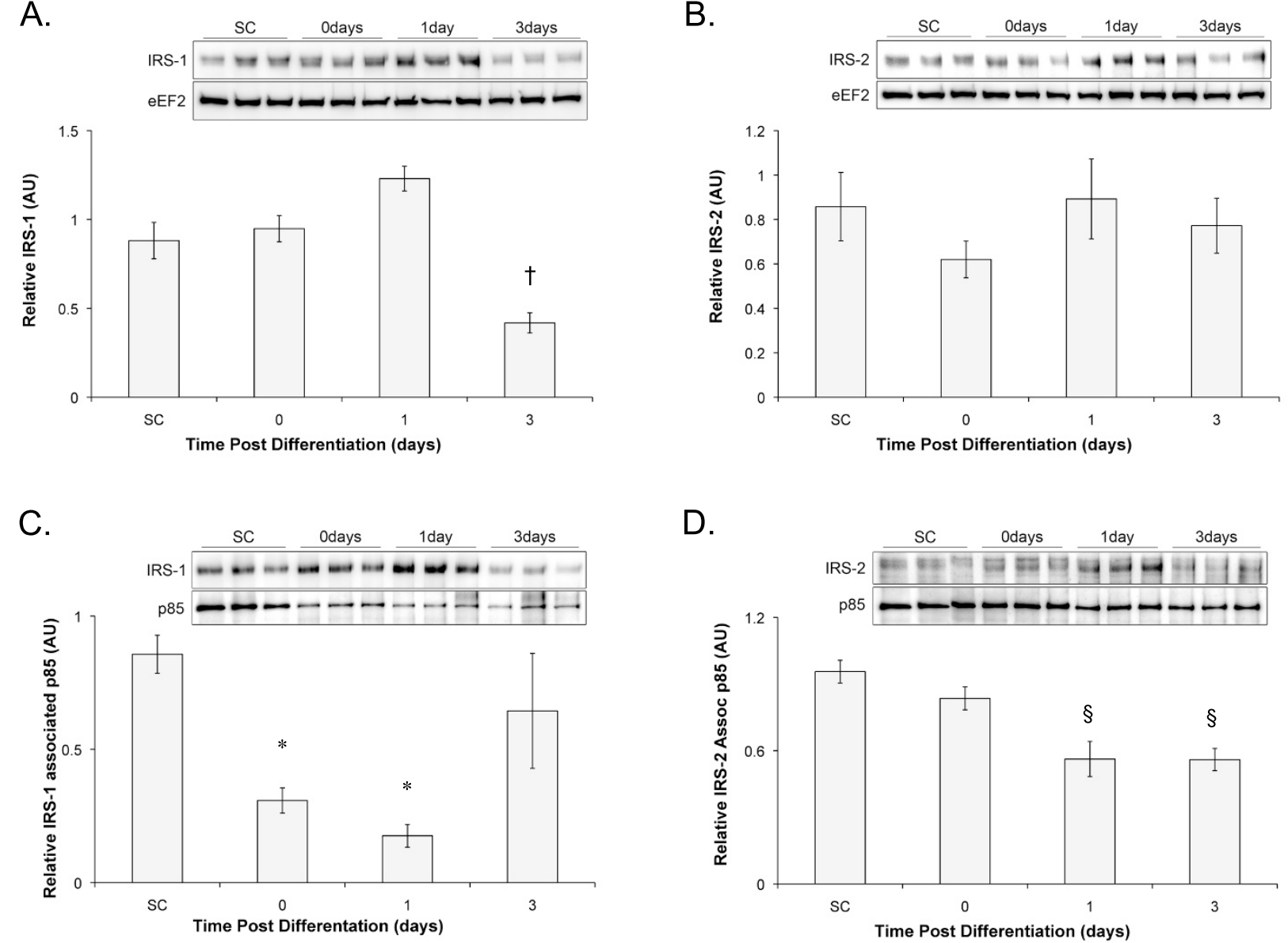

Figure 3 IRS-1/2 expression and associated p85 decrease throughout differentiation. A) IRS-1 and B) IRS-2 total protein was measured via western blots and normalised to relative eEF2 protein content and C) IRS-1 and D) IRS-2 associated p85 was determined as described in methods. All measures were made at 3 (subconfluent; SC), 24 (Day 0), 48 (Day 1), or 96 hours (Day 3) following plating. * indicates significantly different from SC, $\dagger$ indicates significantly different from all other time points, $§$ indicates significantly different from SC and Day 0.

have suggested that cadherins can activate PKB during differentiation, but this has previously been attributed to Rho kinase [4] or Cdo/JLP [5] dependent activation of p38. The current data suggest a more direct mode of activation is possible: the direct recruitment of PI3K, possibly in association with a permissive level of activated IRS1 , to the membrane and the local production of $\mathrm{PIP}_{3}$. While the cadherins have yet to be definitively identified as the phospho-tyrosine containing protein that increases its interaction with p85 during differentiation, the location, function, and dynamics of cadherins during differentiation are all suggestive of a role for these proteins.

Our profile of PKB phosphorylation differs from that previously published $[29,30]$. We observed a biphasic response, whereas others observe a linear increase in PKB phosphorylation at Ser473 and Thr308 [29,30]. This discrepancy could be due to the differentiation protocol used. We include data from cells at subconfluence and withdraw serum at $90-100 \%$ confluence whilst Deldicque et al [29] withdrew serum at 70\% confluence. Gonzalez et al. [31] include data from cells at subconfluence however they collected their cells at a higher confluence and they plated their cells on gelatin coated plates which could affect the cell surface receptors that may be involved in PKB activation. These differences may explain why Gonzalez et al. did not observe an initial reduction in PKB Thr308 phosphorylation upon reaching confluence. Using a similar protocol and measuring PKB activity directly, Cuenda and Cohen observed the same increase in PKB activity 1.5 days following serum withdrawal followed by a decrease at day 3 [15]. These results highlight the importance of maintaining a consistent protocol for differentiation studies.

\section{Conclusions}

Reducing S6K1 protein in differentiating myoblasts does not prevent the loss of IRS-1 at Day 3 of differentiation or 
A.

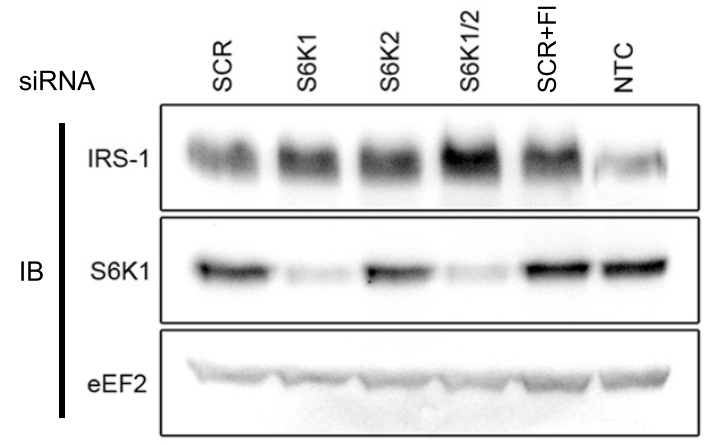

B.

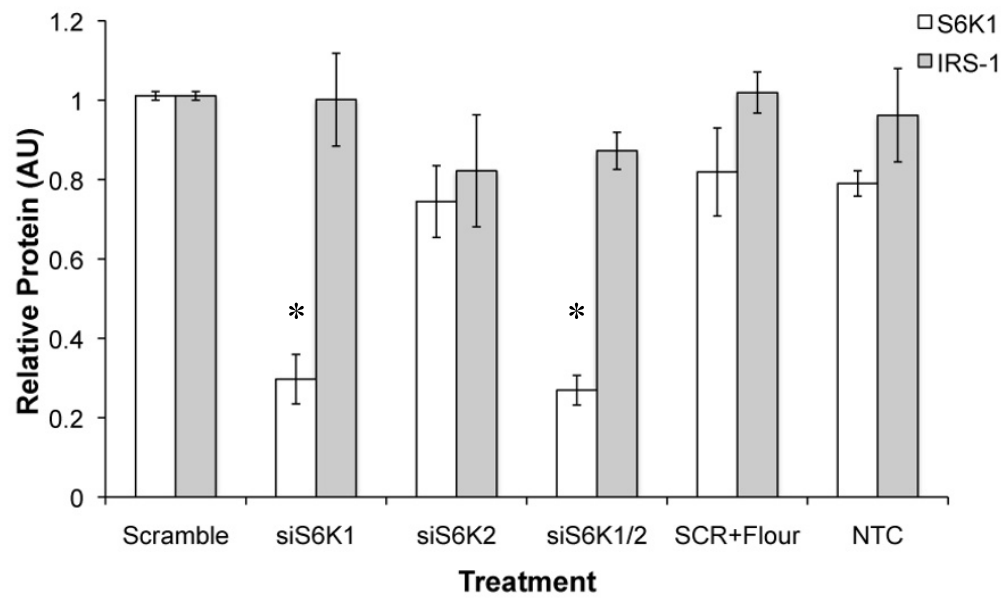

C.

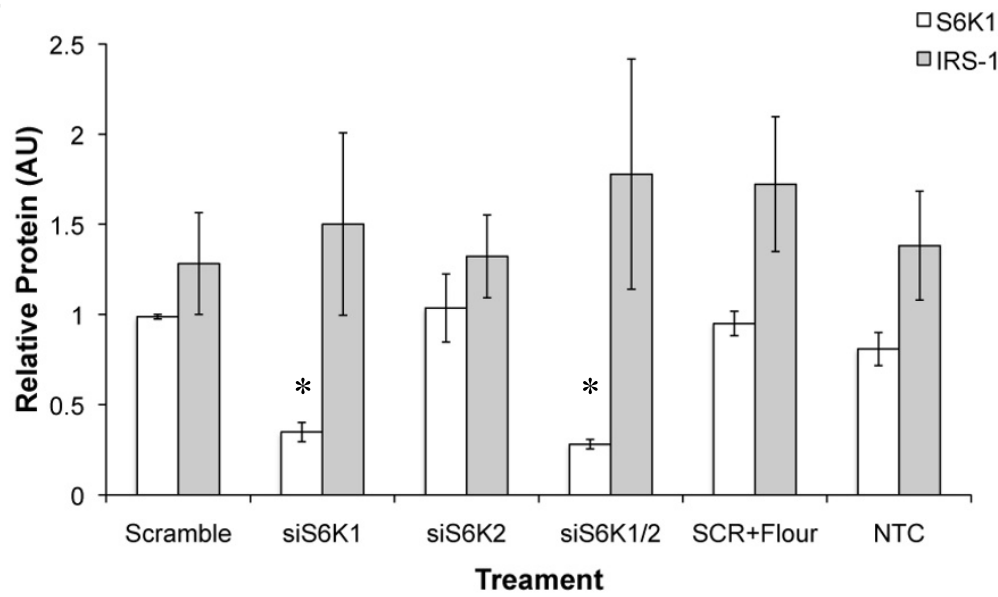

D.

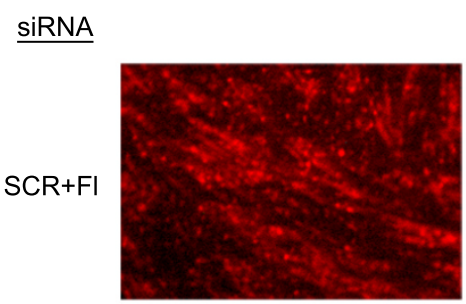

NTC

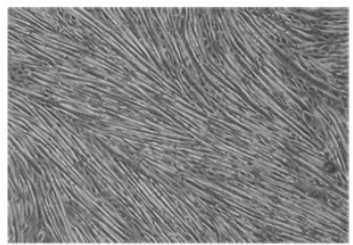

SCR

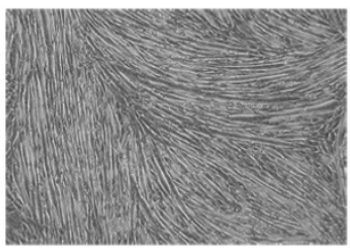

S6K1

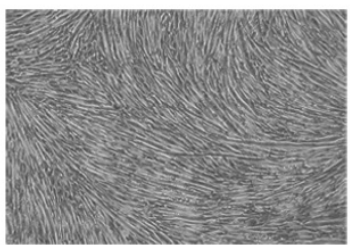

S6K2

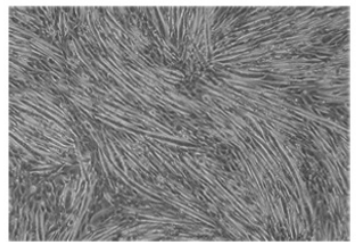

$1 \& 2$

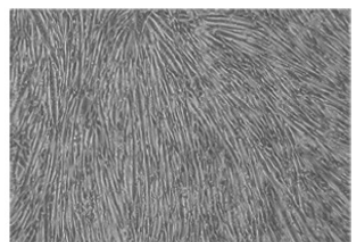

Figure 4 S6K1 siRNA knockdown does not affect IRS-1 protein or muscle cell differentiation. A) Representative Blots, B) IRS-1 and S6K1 expression following treatment with siRNA directed against S6K1 and S6K2 for 48hrs post transfection (cells transfected at SC and collected at Day 1), C) IRS1 and S6K1 levels relative to eEF2 following treatment with siRNA directed against S6K1 and S6K2 for 96 hrs (cells transfected at SC and collected at Day 3), D) Representative images of myotube formation following 96hrs siRNA treatment. Figure headings $-\mathrm{SCR}=$ scramble control siRNA, S6K1 $=$ siRNA against S6K1, S6K2 = siRNA against S6K2, S6K1/2 = siRNA against both S6K1\&2, SCR+FI = scramble control plus a fluorescent tagged siRNA, NTC $=$ no treatment control. ${ }^{*}$ indicates significantly differently different from all other treatments.

improve muscle cell differentiation, suggesting that there are physiological situations when S6K1 is activated and yet IRS-1 is not adversely affected. Furthermore, IRS-1/2 do not appear to contribute substantially to overall PI3K activity during muscle cell differentiation, suggesting that other, as yet undetermined proteins, mediate this essential aspect of muscle cell differentiation. 


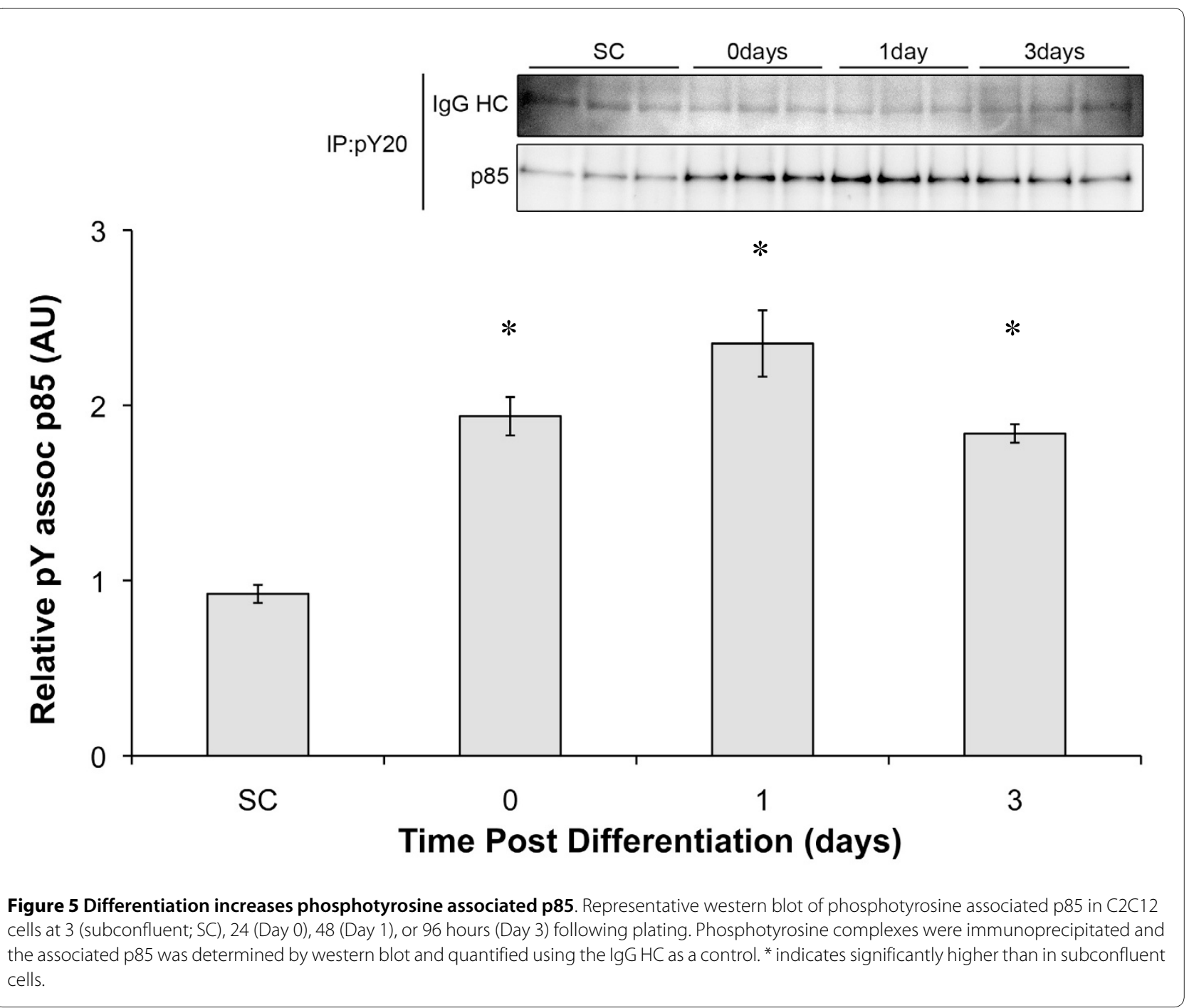

\section{Methods}

Materials

All plasticware for tissue culture was from Greiner (VWR, UK). Tissue culture media and sera were from Invitrogen. Anti-IRS-1 and anti-IRS-2 antibodies were obtained from the Division of Signal Transduction Therapy (DSTT; University of Dundee). pY20 was obtained from BD Biosystems (New Jersey, USA). Total myosin heavy chain (MF20) and the myogenin (F5D) antibodies were obtained from the Developmental Studies Hybridoma Bank developed under the auspices of the NICHD and maintained by The University of Iowa, Department of Biological Sciences, Iowa City, IA 52242. Antibodies for $\mathrm{p}-\mathrm{PKB}^{\mathrm{T} 308}, \mathrm{t}$-eEF2, S6K ${ }^{\mathrm{T} 389}$, p-p44/42 Thr202/Tyr204, $\mathrm{t}$ $\mathrm{p} 44 / 42$, and $\mathrm{t}-\mathrm{PKB}$ were from Cell Signaling Technologies and were used at 1:1000. The total S6K antibody was from Santa Cruz Biotechnologies and was used at 1:1000. Secondary antibodies were from Perbio Science (Cramlington, UK) and used at 1:10000. All phospho-specfic antibodies were quantified relative to their total protein, whereas IRS- $1 / 2$ and $\mathrm{MHC}$ were quantified relative to eEF2. Total eEF2 protein content was unchanged by any of the treatment or interventions. Thr308 phosphorylation was used to measure the effects of differentiation of $\mathrm{PKB}$ since this is the primary $\mathrm{PI}(3,4,5) \mathrm{P}_{3}$-dependent site [32] and therefore the most directly regulated by IRS $-1 / 2$. Chemicals were from Sigma-Aldrich unless stated otherwise.

\section{Tissue culture and transfection}

C2C12 myoblasts were grown in growth media [Dulbecco's Modified Eagle's Medium (DMEM) supplemented with $10 \%$ fetal bovine serum (FBS) and $1 \%$ penicillin/streptomycin]. Myoblasts were kept below $60 \%$ confluence to prevent confluence-induced differentiation. Cells for immunohistochemistry were plated at approximately 200000 cells/well in 6-well plates on collagen coated coverslips and fixed after 3 hrs (subconfluent) 
or at confluence (24 hr; time Day 0 ). On the remaining cells, the media was changed to differentiation media (DMEM supplemented with $2 \% \mathrm{HS}$ and $1 \%$ penicillin/ streptomycin). Cells were then fixed 24 hrs (Day 1) or 72 hrs (Day 3) following differentiation. Cells for immunoprecipitations, kinase assays and western blots were plated on $10 \mathrm{~cm}$ plates at 1.2 million cells per plate and differentiated as above. Each experiment was performed on three separate occasions with $n=4$ for each experiment. Data presented is representative data from a single experiment.

\section{RNA interference of S6K1 and S6K2}

Specific siRNA was designed using the siGENOME SMARTpool approach (Dharmocon RNAi Techonlogies, Thermo Scientific, UK) based on the mouse sequence for S6K1 (NM_028259) and S6K2 (NM_021485). Prior to transfection with siRNA, cells were seeded on 12 well plates at 80000 cells per well with the transfection carried out 3 hours following seeding. Cells were washed $\times 3$ with sterile PBS and $1 \mathrm{ml}$ serum and antibiotic free DMEM was added to the cells prior to the addition of transfection medium. The transfection medium consisted of $200 \mathrm{nmol}$ of siRNA and an equal amount (1:1) of lipofectamine 2000 reagent suspended in optimem transfection media (Invitrogen, UK). siRNA was conjugated with lipofectamine for $30 \mathrm{~min}$ before being added to the cells for $18 \mathrm{~h}$. At the end of 18 hours, cells were washed $\times 3$ with PBS and moved to differentiation media. Mouse ONTARGETplus Non-targeting siRNA (\# D-001810-10, Dharmacon RNAi technologies) was used as a control during all experiments, whilst siGLO (Dharmacon RNAi technologies) was used to assess primary and secondary transfection efficiency.

\section{Protein extraction and SDS-PAGE}

At the allocated time points, cells were washed with ice cold PBS and lysed in sucrose lysis buffer (50 mM Tris pH7.5, 250 mM Sucrose, 1 mM EDTA, 1 mM EGTA, 1\% Triton $\times 100,50 \mathrm{mM} \mathrm{NaF}, 1 \mathrm{mM} \mathrm{NaVO} \mathrm{Na}_{2}\left(\mathrm{PO}_{4}\right)_{2}$ and $0.1 \%$ DTT). The lysate was briefly vortexed and centrifuged at $4^{\circ} \mathrm{C}$ for $10 \mathrm{mins}$ at $11000 \mathrm{rpm}$ to remove insoluble material. Protein concentrations were determined using the DC protein assay (Bio-Rad, Hercules CA). Equal aliquots of protein were diluted in Laemmli sample buffer and boiled for 5 mins. 5-10 $\mu$ g of sample was then subjected to SDS-PAGE on $10 \%$ acrylamide gels and transferred to Protran nitrocellulose membrane (Whatman, Dassel, Germany) and blocked in 5\% dry milk in TBS-T.

\section{Immunobloting}

Membranes were incubated in phosphospecific antibodies overnight at $4^{\circ} \mathrm{C}$, washed and then incubated in HRP conjugated secondaries at 1:10000 for $1 \mathrm{hr}$ at room temperature. Following a final wash, the membranes were incubated in Immobilon $^{\mathrm{TM}}$ Western Chemiluminescent HRP Substrate (Millipore, Billerica, MA) and exposed in a Chemigenius Bio-imaging System (Syngene, Cambridge, UK). The membranes were then stripped in Restore $^{\mathrm{TM}}$ Western Blot Stripping Buffer (Pierce, Rockford, IL) for 20 mins and reprobed for total protein content. All phosphorylation specific antibodies were normalised to the relevant total protein antibody when available, or to eEF2 when this was not possible.

\section{S6K1 activity assay}

S6K1 activity was measured as previously described [33]. Briefly, endogenous S6K1 was immunoprecipitated from $1 \mathrm{mg}$ total protein for 2 hours at $4^{\circ} \mathrm{C}$ with $1 \mu \mathrm{g}$ of rabbit anti-S6K1. S6K1 protein was then immobilised on protein-G sepharose for one hour. Immunocomplexes were washed one time in high detergent buffer A (1\% NP40, $100 \mathrm{mM} \mathrm{NaCl}, 10 \mathrm{mM}$ Tris pH 7.2, 1 mM EDTA), two times in high salt buffer B ( $1 \mathrm{M} \mathrm{NaCl}, 0.1 \% \mathrm{NP}-40,10 \mathrm{mM}$ Tris $\mathrm{pH}$ 7.2), and one time in ST buffer (150 mM NaCl, 50 $\mathrm{mM}$ Tris $\mathrm{pH}$ 7.2). The immunocomplexes were resuspended in $20 \mu \mathrm{l}$ of $1.5 \times$ kinase buffer $(200 \mathrm{mM}$ Hepes $\mathrm{pH}$ 7.2, $100 \mathrm{mM} \mathrm{MgCl}$, $1 \mathrm{mg} / \mathrm{ml}$ BSA. 1:3000 2-Mercaptoethanol) and the activity towards a recombinant GST-S6 peptide was assayed for $10 \mathrm{mins}$ at $30^{\circ} \mathrm{C}$. Reactions were initiated and terminated using $10 \mu \mathrm{l}$ ATP mix $(50 \mu \mathrm{M}$ unlabelled ATP, $5 \mu \mathrm{Ci}$ of [ $\left.\gamma^{-32} \mathrm{P}\right]$ ATP, $1 \mu \mathrm{l}$ GST-S6) and 4 $\times$ LSB (0.5 M Tris pH 6.8, 0.8\% SDS, 20\% 2-Mercaptoethanol, 30\% Glycerol), respectively. Reactions were subjected to $10 \%$ SDS-PAGE and incorporation of $32 \mathrm{P}$ into GST-S6 was assessed by autoradiography and quantified using a Chemi Genius Bioimaging Gel Doc System (Syngene, Cambridge, UK).

\section{Immunocytochemistry}

Coverslips containing cells (see above) were rinsed twice in room temperature PBS before being fixed in $4 \%$ paraformaldehyde for 20 mins. Coverslips were then rinsed 3 times in PBS and aldehydes were quenched in $100 \mathrm{mM}$ glycine for 15 mins before rinsing 3 times in $0.2 \%$ fish skin gelatine (made in PBS). Coverslips were then blocked in Goat Serum (1:10, 0.2\% FSG; Jackson ImmunoResearch Europe) for 10 mins, and rinsed once in $0.2 \%$ FSG before being incubated in primary antibodies [MyoD1 (Novocastra Laboratories) prepared according to the manufacturer's instructions at 1:50 or Myogenin/F5D at 1:50] for 20 mins at room temperature. Primary was rinsed 3 times with $0.2 \%$ FSG before being placed in secondary [Alexa Fluor 488 (Invitrogen) at 1:500, with DAPI at 1:1000 using an $10 \mu \mathrm{g} / \mu \mathrm{l}$ stock]. Secondary was rinsed off 3 times with $0.2 \%$ FSG and 3 times in MiliQ water before being blotted dry and mounted in Vectashield ${ }^{\circ}$ Mounting Medium 
(Vector Laboratories). Coverslips were then analyzed on a fluorescent microscope. To analyze MyoD and Myogenin expression, 5 different fields were counted for DAPI positive nuclei and MyoD/Myogenin positive nuclei.

\section{Statistics}

All data are represented as mean \pm standard error and significance was determined using the Brightstat statistical package http://www.brightstat.com using ANOVA with posthoc analysis by Tukey's Honestly Significant Difference test.

\section{Authors' contributions}

DLH carried out the cell experiments, pulldowns and blots and drafted the manuscript. AP assisted with cell culture, carried out some of the immunoblots and helped to draft the manuscript. MGM carried out the $56 \mathrm{~K}$ assays. KB conceived the study, and participated in its design and coordination and helped to draft the manuscript. All authors read and approved the final manuscript.

\section{Acknowledgements}

DLH is funded by a BBSRC PhD studentship. This work was funded by a Welcome Trust Project Grant 077426/Z/05/Z.

\section{Author Details}

Division of Molecular Physiology, James Black Centre, University of Dundee, Dundee, UK

Received: 18 November 2009 Accepted: 27 May 2010

Published: 27 May 2010

\section{References}

1. Chen EH, Olson EN: Towards a molecular pathway for myoblast fusion in Drosophila. Trends Cell Biol 2004, 14(8):452-460.

2. Carlson BM: Some principles of regeneration in mammalian systems. Anat Rec B New Anat 2005, 287(1):4-13.

3. Puente LG, Voisin S, Lee RE, Megeney LA: Reconstructing the regulatory kinase pathways of myogenesis from phosphopeptide data. Mol Cell Proteomics 2006, 5(12):2244-51.

4. Lovett FA, Gonzalez I, Salih DA, Cobb LJ, Tripathi G, Cosgrove RA, Murrell A, Kilshaw PJ, Pell JM: Convergence of Igf2 expression and adhesion signalling via RhoA and p38 MAPK enhances myogenic differentiation. J Cell Sci 2006, 119(Pt 23):4828-4840.

5. Takaesu G, Kang JS, Bae GU, Yi MJ, Lee CM, Reddy EP, Krauss RS: Activation of p38alpha/beta MAPK in myogenesis via binding of the scaffold protein JLP to the cell surface protein Cdo. J Cell Bio/ 2006, 175(3):383-388

6. Lluis F, Perdiguero E, Nebreda AR, Munoz-Canoves P: Regulation of skeletal muscle gene expression by p38 MAP kinases. Trends Cell Biol 2006, 16(1):36-44

7. Rosen KM, Wentworth BM, Rosenthal N, Villa-Komaroff L: Specific, temporally regulated expression of the insulin-like growth factor II gene during muscle cell differentiation. Endocrinology 1993 133(2):474-481

8. Ewton DZ, Falen SL, Florini JR: The type II insulin-like growth factor (IGF) receptor has low affinity for IGF-I analogs: pleiotypic actions of IGFs on myoblasts are apparently mediated by the type I receptor. Endocrinology 1987, 120(1):115-123.

9. Florini JR, Ewton DZ, Coolican SA: Growth hormone and the insulin-like growth factor system in myogenesis. Endocr Rev 1996, 17(5):481-517.

10. Vandromme M, Rochat A, Meier R, Carnac G, Besser D, Hemmings BA, Fernandez A, Lamb NJ: Protein kinase B beta/Akt2 plays a specific role in muscle differentiation. J Bio/ Chem 2001, 276(11):8173-8179.

11. Velden $J$ van der, Langen RC, Kelders MC, Wouters EF, Janssen-Heininger YM, Schols AM: Inhibition of glycogen synthase kinase-3beta activity is sufficient to stimulate myogenic differentiation. Am J Physio/ Cell Physiol 2006, 290(2):C453-462.
12. Kaneko S, Feldman RI, Yu L, Wu Z, Gritsko T, Shelley SA, Nicosia SV, Nobori T, Cheng JQ: Positive feedback regulation between Akt2 and MyoD during muscle differentiation. Cloning of Akt2 promoter. J Bio/ Chem 2002, 277(26):23230-23235.

13. Inoki K, Li Y, Zhu T, Wu J, Guan KL: TSC2 is phosphorylated and inhibited by Akt and suppresses mTOR signalling. Nat Cell Bio/ 2002, 4(9):648-657.

14. Erbay $\mathrm{E}$, Chen J: The mammalian target of rapamycin regulates $\mathrm{C} 2 \mathrm{C} 12$ myogenesis via a kinase-independent mechanism. J Biol Chem 2001, 276(39):36079-36082

15. Cuenda A, Cohen P: Stress-activated protein kinase-2/p38 and a rapamycin-sensitive pathway are required for $\mathrm{C} 2 \mathrm{C} 12$ myogenesis. $J$ Biol Chem 1999, 274(7):4341-4346

16. Park IH, Chen J: Mammalian target of rapamycin (mTOR) signaling is required for a late-stage fusion process during skeletal myotube maturation. J Biol Chem 2005, 280(36):32009-32017.

17. Harrington LS, Findlay GM, Gray A, Tolkacheva T, Wigfield S, Rebholz H, Barnett J, Leslie NR, Cheng S, Shepherd PR, Gout I, Downes CP, Lamb RF: The TSC1-2 tumor suppressor controls insulin-PI3K signaling via regulation of IRS proteins. J Cell Biol 2004, 166(2):213-223.

18. Tremblay F, Marette A: Amino acid and insulin signaling via the mTOR/ p70 S6 kinase pathway. A negative feedback mechanism leading to insulin resistance in skeletal muscle cells. J Biol Chem 2001 , 276(41):38052-38060

19. Zick Y: Ser/Thr phosphorylation of IRS proteins: a molecular basis for insulin resistance. SCiSTKE 2005, 2005(268):pe4.

20. Park $I H$, Erbay E, Nuzzi $P$, Chen J: Skeletal myocyte hypertrophy requires mTOR kinase activity and S6K1. Exp Cell Res 2005, 309(1):211-219.

21. Bouzakri K, Zachrisson A, Al-Khalili L, Zhang BB, Koistinen HA, Krook A, Zierath JR: siRNA-based gene silencing reveals specialized roles of IRS1/Akt2 and IRS-2/Akt1 in glucose and lipid metabolism in human skeletal muscle. Cell Metab 2006, 4(1):89-96.

22. Zong H, Bastie CC, Xu J, Fassler R, Campbell KP, Kurland IJ, Pessin JE: Insulin Resistance in Striated Muscle-specific Integrin Receptor \{beta\}1-deficient Mice. J Biol Chem 2009, 284(7):4679-4688.

23. Tan C, Costello P, Sanghera J, Dominguez D, Baulida J, de Herreros AG, Dedhar S: Inhibition of integrin linked kinase (ILK) suppresses betacatenin-Lef/Tcf-dependent transcription and expression of the Ecadherin repressor, snail, in APC-/- human colon carcinoma cells. Oncogene 2001, 20(1):133-140

24. Hannigan GE, Leung-Hagesteijn C, Fitz-Gibbon L, Coppolino MG, Radeva G, Filmus J, Bell JC, Dedhar S: Regulation of cell adhesion and anchorage-dependent growth by a new beta 1-integrin-linked protein kinase. Nature 1996, 379(6560):91-96.

25. Sarbassov DD, Guertin DA, Ali SM, Sabatini DM: Phosphorylation and Regulation of Akt/PKB by the Rictor-mTOR Complex. Science 2005, 307(5712):1098-1101

26. Gavard J, Marthiens V, Monnet C, Lambert M, Mege RM: N-cadherin activation substitutes for the cell contact control in cell cycle arrest and myogenic differentiation: involvement of p120 and beta-catenin. J Biol Chem 2004, 279(35):36795-36802.

27. Pang JH, Kraemer A, Stehbens SJ, Frame MC, Yap AS: Recruitment of phosphoinositide 3-kinase defines a positive contribution of tyrosine kinase signaling to E-cadherin function. J Biol Chem 2005, 280(4):3043-3050

28. Shin CS, Lecanda F, Sheikh S, Weitzmann L, Cheng SL, Civitelli R: Relative abundance of different cadherins defines differentiation of mesenchymal precursors into osteogenic, myogenic, or adipogenic pathways. J Cell Biochem 2000, 78(4):566-577.

29. Deldicque L, Theisen D, Bertrand L, Hespel P, Hue L, Francaux M: Creatine enhances differentiation of myogenic $\mathrm{C} 2 \mathrm{C} 12$ cells by activating both p38 and Akt/PKB pathways. Am J Physiol Cell Physiol 2007, 293(4):C1263-1271.

30. Gonzalez I, Tripathi G, Carter EJ, Cobb LJ, Salih DA, Lovett FA, Holding C, Pell JM: Akt2, a novel functional link between p38 mitogen-activated protein kinase and phosphatidylinositol 3-kinase pathways in myogenesis. Mol Cell Biol 2004, 24(9):3607-3622.

31. Gonzales JA, Szeto A, Mendez AJ, Zaias J, Paredes J, Caperton CV, Llabre MM, Levine JE, Goldberg RB, Schneiderman N, McCabe PM: Effect of behavioral interventions on insulin sensitivity and atherosclerosis in the Watanabe heritable hyperlipidemic rabbit. Psychosom Med 2005, 67(2):172-178 
32. Alessi DR, James SR, Downes CP, Holmes AB, Gaffney PR, Reese CB, Cohen $P$ : Characterization of a 3-phosphoinositide-dependent protein kinase which phosphorylates and activates protein kinase Balpha. Curr Biol 1997, 7(4):261-269.

33. Mackenzie MG, Hamilton DL, Murray JT, Baar K: $\mathrm{mVps} 34$ is activated by an acute bout of resistance exercise. Biochem Soc Trans 2007, 35(Pt 5):1314-1316.

doi: $10.1186 / 1471-2121-11-37$

Cite this article as: Hamilton et al., Prolonged activation of S6K1 does not suppress IRS or PI-3 kinase signaling during muscle cell differentiation BMC Cell Biology 2010, 11:37

Submit your next manuscript to BioMed Central and take full advantage of:

- Convenient online submission

- Thorough peer review

- No space constraints or color figure charges

- Immediate publication on acceptance

- Inclusion in PubMed, CAS, Scopus and Google Scholar

- Research which is freely available for redistribution

Submit your manuscript at www.biomedcentral.com/submit 